\title{
Investigation method of borehole collapse with the multi-field coupled model during drilling in clayey silt hydrate reservoirs
}

\author{
Qing-Chao Li, Yuan-Fang Cheng, Qiang Li \\ School of Petroleum Engineering, China University of Petroleum (East China), Qingdao, Shandong 266580, China. \\ B16020053@s.upc.edu.cn http://orcid.or/0000-0001-7373-4046 \\ yfcheng@upc.edu.cn \\ bttp:/ / orcid.org/0000-0001-7181-9919
}

Fu-ling Wang

College of Science, China University of Petroleum (East China), Qingdao, Shandong 266580, China.

Chuang Zhang, Chuan-liang Yan

School of Petroleum Engineering, China University of Petroleum (East China), Qingdao, Shandong 266580, China.

\begin{abstract}
The global reserves of natural gas hydrates are extremely abundant, but hydrate reservoirs are usually clayey silt hydrate reservoirs with low strength, and borehole collapse is a key issue during the drilling operation. In the present work, both the investigation method and the finite element model that used for investigating borehole collapse in hydratebearing sediment are developed, and the superiority of the investigation method developed herein is also analyzed. The results show that changes in temperature and/or pore pressure do not necessarily lead to the hydrate dissociation. Hydrate dissociation occurs only when both temperature and pore pressure satisfy the conditions of hydrate dissociation. Moreover, the applicability of the investigation method developed herein is verified by comparing the equivalent plastic strains obtained by the coupled model developed in this paper and the simplified model respectively. In addition, the simplified model overestimates the extent of the wellbore collapse for the drilling operation in hydrate-bearing sediments. All these results demonstrate that both the investigation method and the finite element model can be used for borehole stability simulation in hydrate-bearing sediments.
\end{abstract}

KEYWORDS. Hydrate-bearing sediments; Hydrate dissociation; Wellbore instability; Borehole collapse; Finite element analysis.

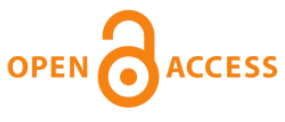

Citation: Li, Q. C., Cheng, Y. F., Li, Q., Wang, F. L., Wei, J., Ding, J. P., Zhang, H. W., Song, B. J., Zhang, C., Yan, C. L., Investigation method of borehole collapse with the multi-field coupled model during drilling in clayey silt hydrate reservoirs, Frattura ed Integrità Strutturale, 45 (2018) 8699.

Received: 19.05 .2018

Accepted: 25.05 .2018

Published: 01.07.2018

Copyright: (C) 2018 This is an open access article under the terms of the CC-BY 4.0, which permits unrestricted use, distribution, and reproduction in any medium, provided the original author and source are credited.

\section{INTRODUCTION}

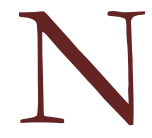

atural gas hydrates are crystalline structures formed by natural gases (mainly methane, generally more than 96\%) and pure water under the conditions of low temperature and high pressure [1-3]. More and more attention has been paid to methane hydrate development from hydrate-bearing sediments in deep water for its clean property 
and the vast reserves. Although the estimation of global hydrate reserves is uncertain, according to incomplete statistics, the energy stored in natural gas hydrates all over the world is at least twice as much as that stored in fossil fuels currently known [4-6]. Although various countries have conducted a series of hydrate production test activities recently (especially China and Japan), the current research on methane hydrates is generally in the stage of theoretical research and laboratory exploration. The production test activities are listed in Tab. 1.

\begin{tabular}{|c|c|c|c|c|c|c|}
\hline & \multicolumn{2}{|c|}{ Canada } & \multirow{2}{*}{$\begin{array}{l}\text { U.S.A } \\
1^{\text {st }} \text { test }\end{array}$} & \multicolumn{2}{|c|}{ Japan } & \multirow{2}{*}{$\begin{array}{l}\text { China } \\
1^{\text {st }} \text { test }\end{array}$} \\
\hline & $1^{\text {st }}$ test & $2^{\text {nd }}$ test & & $1^{\text {st }}$ test & $2^{\text {nd }}$ test & \\
\hline Time & 2002 & 2007 & 2012 & 2013 & 2017 & 2017 \\
\hline Test area & \multicolumn{2}{|c|}{ Mackenzie Delta } & $\begin{array}{c}\text { North Slope of } \\
\text { Alaska }\end{array}$ & \multicolumn{2}{|c|}{ Nankai Trough } & $\begin{array}{l}\text { Shenhu } \\
\text { area }\end{array}$ \\
\hline Lithology & \multicolumn{2}{|c|}{ Sandy } & Sandy & \multicolumn{2}{|c|}{ Sandy } & Clayey silt \\
\hline Method & $\begin{array}{l}\text { Hot water } \\
\text { circulating }\end{array}$ & Depressurization & $\begin{array}{c}\text { Replacement }+ \\
\text { Depressurization }\end{array}$ & \multicolumn{2}{|c|}{ Depressurization } & $\begin{array}{c}\text { Fluid } \\
\text { extraction }\end{array}$ \\
\hline Production time & $5 \mathrm{~d}$ & $6 \mathrm{~d}$ & $30 \mathrm{~d}$ & $6 \mathrm{~d}$ & $36 \mathrm{~d}$ & $60 \mathrm{~d}$ \\
\hline Cumulative gas & $516 \mathrm{~m}^{3}$ & $13000 \mathrm{~m}^{3}$ & $24000 \mathrm{~m}^{3}$ & $120000 \mathrm{~m}^{3}$ & $235000 \mathrm{~m}^{3}$ & $309000 \mathrm{~m}^{3}$ \\
\hline Reasons for stop & - & - & - & Sand $P_{1}$ & iction & \\
\hline
\end{tabular}

Table 1: Production test activities of natural gas hydrates Worldwide [7].

Some development strategies have been studied by numerous experts for the development of natural gas hydrates, of which the depressurization method is the most effective and the most commonly used one [8]. However, hydrate reservoirs in deep water are generally low-strength formations, which make the wellbore collapse to be a commonly occurred issue during hydrate production process [9-12]. In addition, hydrate dissociation during hydrate production operation is another contributor to both the complex accidents within the borehole (i.e., borehole instability and casing damage, etc.)[13-17] and the geological disasters (such as slope slide and submarine earthquakes)[18, 19]. Hydrate dissociation at high temperature and/or low pressure determines that drilling operation in hydrate reservoirs is more difficult than conventional oil and gas reservoirs. The caliper logging curve at the SH4 site in Shenhu area of the South China Sea shows that serious borehole collapse and borehole enlargement has emerged during the drilling process within the hydrate interval [20]. Therefore, exploration of a method for borehole stability investigation in hydrate reservoirs and thorough analysis of borehole collapse mechanism are of great importance to ensure the construction safety in hydrate reservoirs.

Up to now, the main focuses of numerous scholars have been paid on gas production from hydrate-bearing sediments, and different production strategies have been investigated in detail [7, 21-25]. However, the threat of hydrate dissociation to the stability of both the reservoir and wellbore is an important research topic in the development of natural gas hydrates. On the one hand, hydrate dissociation leads to changes in both the pore pressure and the effective stresses within hydrate reservoir. On the other hand, hydrate dissociation also weakens the reservoir strength, which severely affects the strata stability. In spite of this, the investigations of wellbore behavior caused by hydrate dissociation during hydrate development in deep water only attract a few scholars' interests [13-17, 26, 27]. Although these studies are valuable for studying borehole behavior during a drilling operation in hydrate formation, nearly all these related investigations did not integrate three physical fields of seepage, deformation, and heat transfer to thoroughly analyze borehole stability in hydrate reservoirs.

In this paper, the finite element (FE) model used for investigating borehole stability during the drilling operation in hydrate reservoirs is established by integrating seepage, deformation, and heat transfer. Based on this, the results of borehole collapse are compared when the coupled FE model (investigated herein) and the simplified model (both seepage and heat transfer are neglected) are used respectively, then the applicability of the investigation method can be verified. Moreover, the yield range evolution within the near-wellbore area is also investigated with the coupled FE model. 


\section{FUNDAMENTAL THEORY}

\section{Borehole instability in bydrate reservoirs}

TTT ellbore instability usually manifests as shear failure and/or tensile failure. Borehole collapse generally occurs in the direction of the minimum principal stress due to the stress concentration caused by the low drilling mud density $[28,29]$. Hydrate reservoirs are usually sandstone reservoirs with high porosity, and borehole collapse is the main form of borehole instability in hydrate formations. Hydrate dissociation results in the changes of both pore pressure and the effective stresses. Therefore, hydrate dissociation within the near-wellbore region during drilling operation can aggravate the borehole collapse. And, borehole collapse in hydrate reservoirs depends on the initial formation conditions and the conditions of drilling mud within the wellbore. Schematic diagram of borehole instability while drilling in hydrate reservoirs is shown as Fig.1. Therefore, determining the collapse area during a drilling operation in hydrate reservoirs needs to consider the effect of hydrate dissociation caused by the invasion of drilling mud.

During the determination of collapse area, the equivalent plastic strain is used as the parameter for judging the collapse of a wellbore. When the surrounding rock shows a positive equivalent plastic strain value, it is considered that the borehole may collapse.

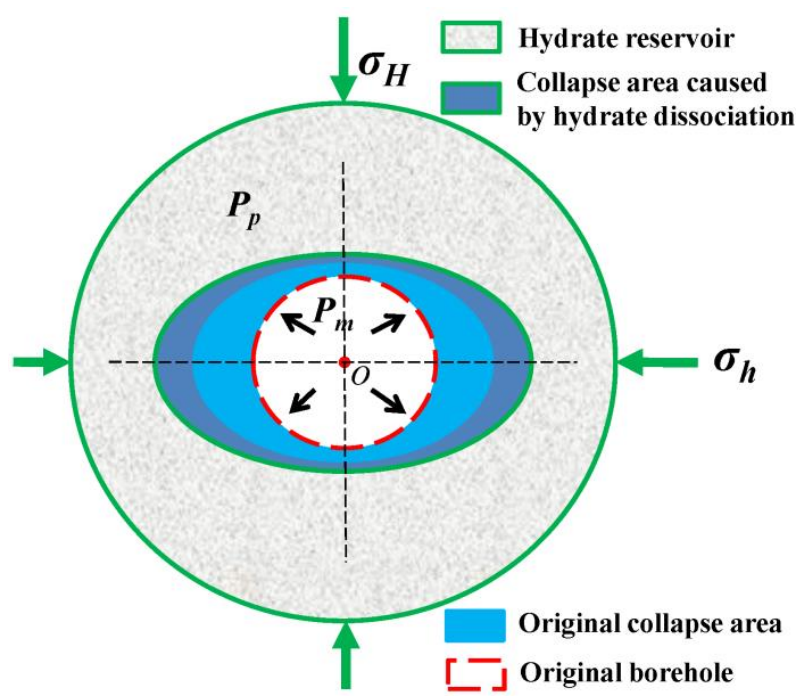

Figure 1: Schematic diagram of borehole instability while drilling in hydrate reservoirs.

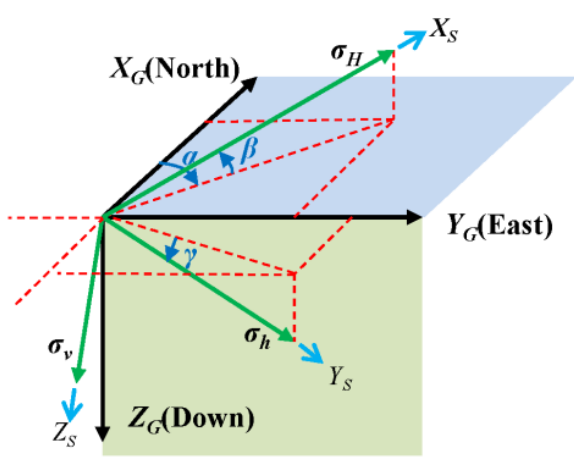

a) Transformation between the in-situ stress coordinate system and the geographic coordinate system.

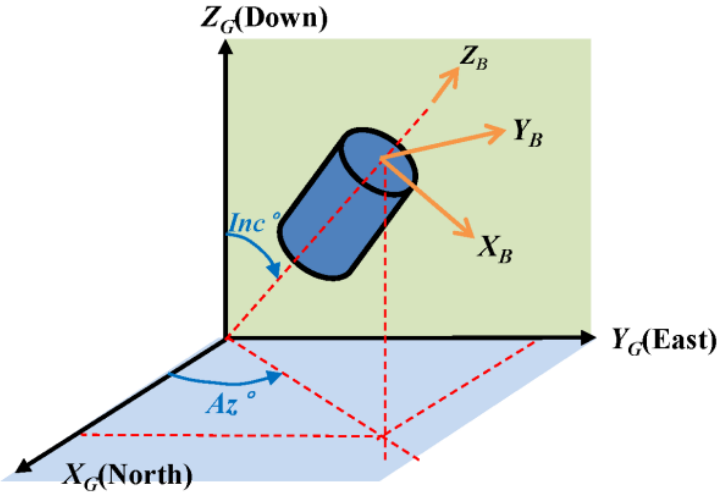

b) Transformation between the geographic coordinate system and the borehole coordinate system

Figure 2: Schematic diagram of the relationship between various coordinate systems.

\section{Effective stresses around arbitrary borehole}

The effective stress is the key for wellbore stability, and the relationship between the total stress, the effective stress and the pore pressure can be expressed by the principle of effective stress, which is shown as the following equation. 


$$
\sigma_{\text {tot }}=\sigma_{e f f}+P_{p}
$$

In order to accurately determine the effective stresses around the arbitrary borehole, four coordinate systems (Fig.2) are defined, that is, the in-situ stress coordinate system $\left(X_{S}-Y_{S}-Z_{S}\right)$, the geographic coordinate system $\left(X_{G^{-}} Y_{G^{-}} Z_{G}\right)$, the borehole coordinate system $\left(X_{B}-Y_{B}-Z_{B}\right)$ and the wellbore polar coordinate system $\left(r-\theta-Z_{B}\right)$.

The in-situ stresses $\left(\sigma_{H}, \sigma_{h}\right.$, and $\left.\sigma_{v}\right)$ can be transformed from the in-situ stress coordinate system to the borehole coordinate system with two transformation steps [30]. Firstly, the in-situ stresses are transformed from the in-situ stress coordinate system to the geographic coordinate system. Then the stresses in geographic coordinate system are transformed from the geographic coordinate system to the borehole coordinate system. The whole transformation process can be expressed by the following equation.

$$
\sigma_{B}=\left\{\begin{array}{ccc}
\sigma_{B}^{x x} & \sigma_{B}^{x y} & \sigma_{B}^{x z} \\
\sigma_{B}^{y x} & \sigma_{B}^{y y} & \sigma_{B}^{y z} \\
\sigma_{B}^{z x} & \sigma_{B}^{y y} & \sigma_{B}^{z z}
\end{array}\right\}=R_{B} R_{S}^{T} \sigma_{P} R_{S} R_{B}^{T}
$$

where the tensor $R_{s}$ and $R_{B}$ are expressed as Eqn. (3) and Eqn. (4).

$$
\begin{aligned}
& R_{S}=\left\{\begin{array}{ccc}
\cos \alpha \cdot \cos \beta & \sin \alpha \cdot \cos \beta & -\sin \beta \\
\cos \alpha \cdot \sin \beta \cdot \sin \gamma-\sin \alpha \cdot \cos \gamma & \sin \alpha \cdot \sin \beta \cdot \sin \gamma+\cos \alpha \cdot \cos \gamma & \cos \beta \cdot \sin \gamma \\
\cos \alpha \cdot \sin \beta \cdot \cos \gamma-\sin \alpha \cdot \sin \gamma & \sin \alpha \cdot \sin \beta \cdot \cos \gamma-\cos \alpha \cdot \sin \gamma & \cos \beta \cdot \cos \gamma
\end{array}\right\} \\
& R_{B}=\left\{\begin{array}{ccc}
\cos (A z) \cos (\operatorname{Inc}) & \sin (A z) \cos (\operatorname{Inc}) & -\sin (\operatorname{In} c) \\
-\sin (A z) & \cos (A z) & 0 \\
\cos (A z) \sin (\operatorname{Inc}) & \sin (A z) \sin (\operatorname{Inc}) & \cos (\operatorname{In} c)
\end{array}\right\}
\end{aligned}
$$

The stresses around borehole in the cylindrical coordinate system can be expressed as Eqn. (5) when the drilling fluid pressure is $P_{m}[31]$.

$$
\begin{aligned}
& \sigma_{r}=P_{m}-P_{p} \\
& \sigma_{\theta}=\sigma_{B}^{x x}+\sigma_{B}^{y y}-2\left(\sigma_{B}^{x x}-\sigma_{B}^{y y}\right) \cos 2 \theta-4 \sigma_{B}^{x y} \sin 2 \theta-P_{m}-P_{p} \\
& \sigma_{z}=\sigma_{B}^{z z}-2 v\left[\left(\sigma_{B}^{x x}-\sigma_{B}^{y y}\right) \cos 2 \theta+2 \sigma_{B}^{x y} \sin 2 \theta\right]-P_{p} \\
& \sigma_{\theta z}=2\left(\sigma_{B}^{y z} \cos \theta-\sigma_{B}^{x z} \sin \theta\right)
\end{aligned}
$$

The maximum and minimum effective principal stresses need to be determined when Mohr-Coulomb criterion is used for borehole stability analysis. However, determining the three effective stresses around borehole $\left(\sigma_{i}, \sigma_{j}\right.$ and $\left.\sigma_{k}\right)$ in borehole cylindrical coordinate system is the basis, which can be calculated using Eqn. (6).

$$
\begin{aligned}
& \sigma_{i}=\sigma_{r}=P_{m}-P_{p} \\
& \sigma_{j}=0.5\left(\sigma_{\theta}+\sigma_{z}\right)+0.5 \sqrt{\left(\sigma_{\theta}-\sigma_{z}\right)^{2}+4 \sigma_{\theta z}^{2}} \\
& \sigma_{k}=0.5\left(\sigma_{\theta}+\sigma_{z}\right)-0.5 \sqrt{\left(\sigma_{\theta}-\sigma_{z}\right)^{2}+4 \sigma_{\theta z}^{2}}
\end{aligned}
$$

The maximum and minimum effective principal stresses can be obtained by comparing these three effective stresses. 


\section{Conditions for bydrate stability}

Loh et al. investigated the dissociation of seawater hydrates $(3.03 \mathrm{wt} \% \mathrm{NaCl})$ and gave the empirical phase boundary equation for methane hydrate in porous media, which is shown as Eqn. (7) [32]. The equation shows that the hydrate will dissociate when the temperature $T$ exceeds the phase equilibrium temperature $T_{e q}$ under the corresponding pore pressure $P_{p}$

$$
P_{e q}=1.3+1.66 \exp \left(0.141 T_{e q}\right)
$$

Eqn. (7) can be used for determining whether the methane hydrate dissociate or not.

\section{FINITE ELEMENT MODEL}

B efore the establishment of the FE model, some assumptions are made to simplify the investigation problem. Firstly, investigation of borehole stability while drilling in hydrate-bearing sediments can be simplified as the plane strain problem. Furthermore, hydrate reservoir is thought of as the isotropic porous media. Also, the temperature of the drilling mud is constant during the whole drilling operation. Finally, the effects of hydrate dissociation on both the temperature and the pore pressure of hydrate reservoir are neglected. However, no matter how the investigation problem is simplified, it is a complex physical process involving physical fields such as seepage, deformation and heat transfer. The established 2D FE model is displayed as Fig.3. As can be seen from Fig.3, the wellbore is assumed as the vertical openhole one drilled in the clayey silt hydrate reservoir. Moreover, the diameter of the borehole is the same as that of the drill bit, and it is $8^{1 / 2}$ inches. In order to ensure that the temperature and pore pressure at the outer boundaries are not affected during the entire simulation, both the length and width of the FE model are $20 \mathrm{~m}$. Herein, the widely used MohrCoulomb constitutive model has been used herein to describe the relationship between the stress and the strain of the porous media.

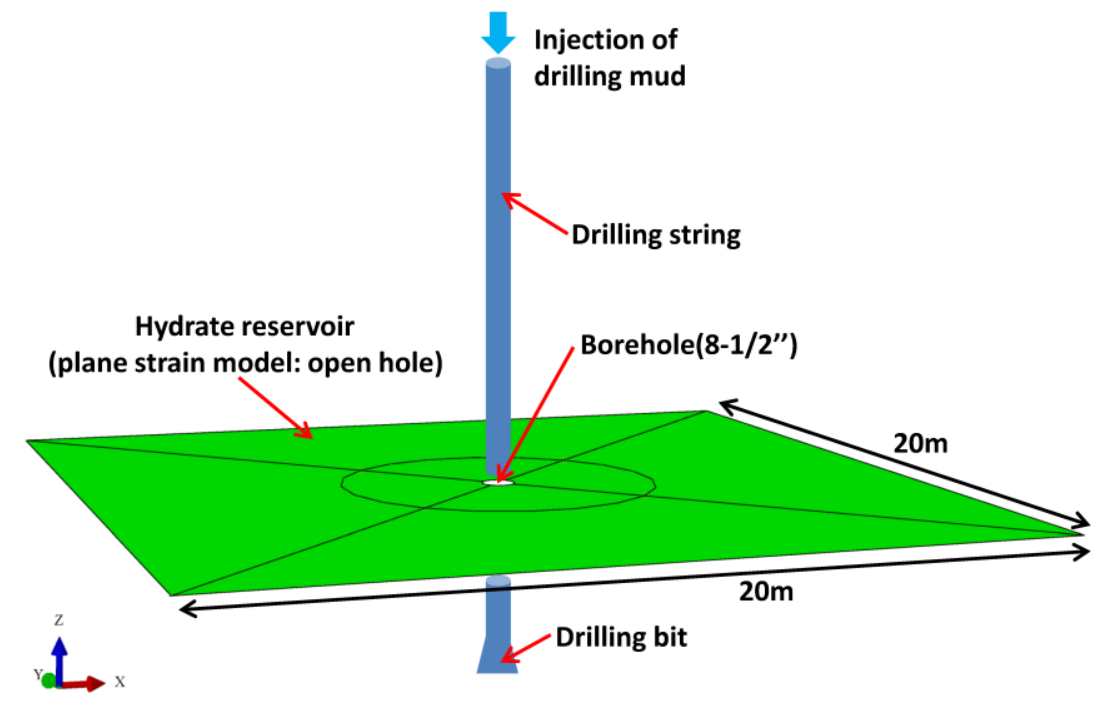

Figure 3: Schematic of borehole stability model during a drilling operation in hydrate reservoir.

\section{Boundary conditions and the initial conditions}

The entire simulation process can be divided into two steps, namely, the geostatic step and the borehole stability analysis step. In the first step, the normal displacements at the outer boundaries of the FE model are fixed. The borehole also needs to be fixed in this step to simulate the state that the hydrate reservoir has not been disturbed. Fig. 4 shows the boundary conditions of the FE model in the first step. And, in order to clearly show the boundary condition of the borehole in this step and the detailed elements within the near-wellbore area, Fig.4b demonstrates the mesh model of the near-wellbore area. 
In the FE model, 4500 stress/pore pressure elements are obtained to simulate the borehole collapse in hydrate formation. Since the hydrate dissociation during drilling operation mainly occurs in the near-wellbore area (Fig.4b), the elements within the near-wellbore area are denser than other area.

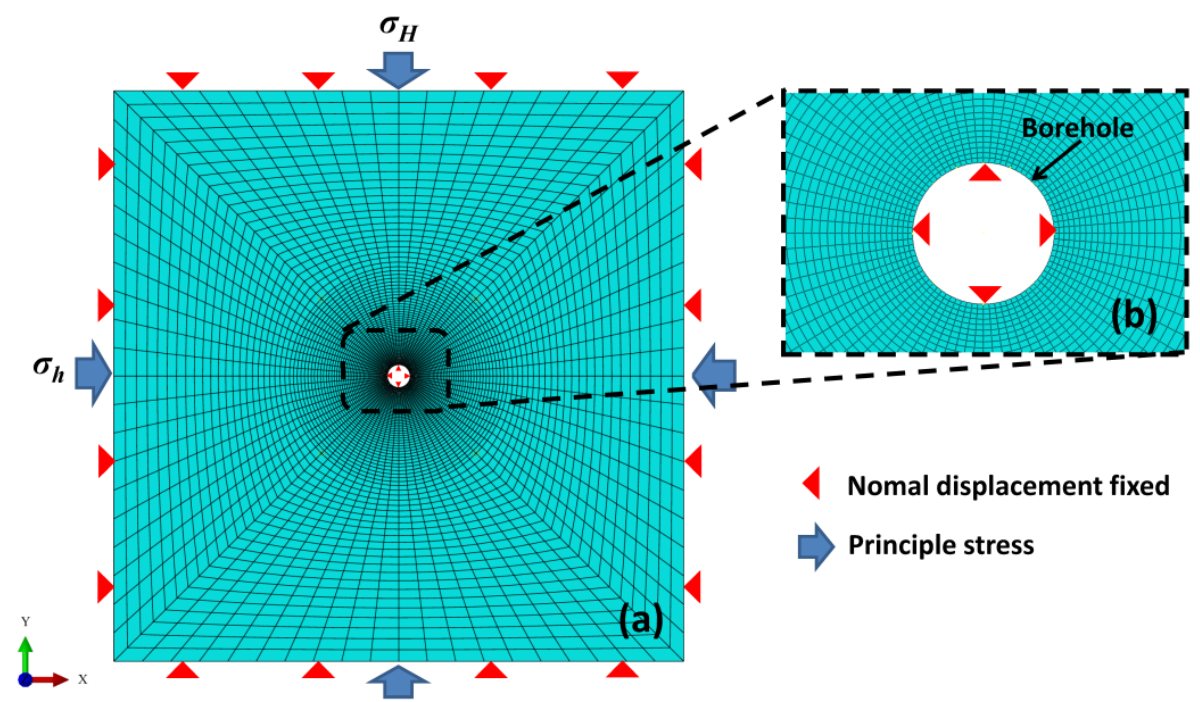

Figure 4: The boundary conditions in the first step (the geostatic step). (a): the whole model, (b) elements in the near-wellbore area.

Just as the first step, Fig.5 demonstrates the boundary conditions of the FE model in the second step (the borehole stability step). In the borehole stability step, the boundary conditions are listed as the following items:

(1) The fixed displacement of borehole should be removed first, which is an alternative to drilling operation;

(2) Then, boundary conditions of both the temperature and pore pressure should be applied to the borehole;

(3) Also, boundary conditions of both the temperature and pore pressure should be applied to the outer boundaries synchronously;

(4) Besides, the bottom-hole pressure $P_{m}$ generated by the gravity of the drilling fluid needs to be applied to the borehole.

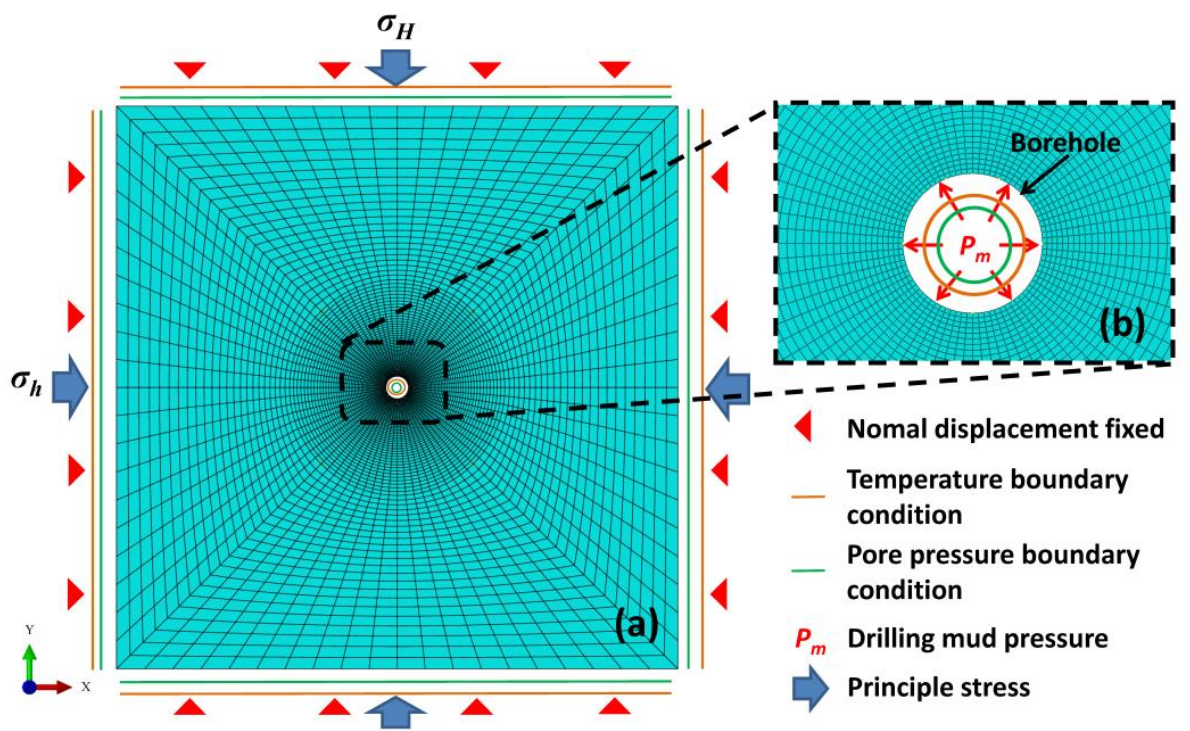

Figure 5: The boundary conditions in the second step (the borehole stability step).

The initial conditions herein are the initial pore pressure and the initial temperature within the hydrate-bearing sediments. In addition, the in-situ stresses also need to be determined. The initial conditions and the boundary conditions can be determined by the logging data and/or the seismic data obtained from exploration activities. 


\section{Simulation methodology and workflow}

According to the load, the initial conditions and the boundary conditions described in these two simulation steps, the investigation methodology and workflow herein is presented as Fig.6. Firstly, the initial stress state without human disturbance within the investigation model for wellbore stability simulation can be generated by the geostatic step. Then, based on the results obtained by the first step, the borehole collapse can be investigated by the second analysis step. However, the focus of the whole simulation is the coupling of the three physical fields of heat transfer, seepage, and deformation.

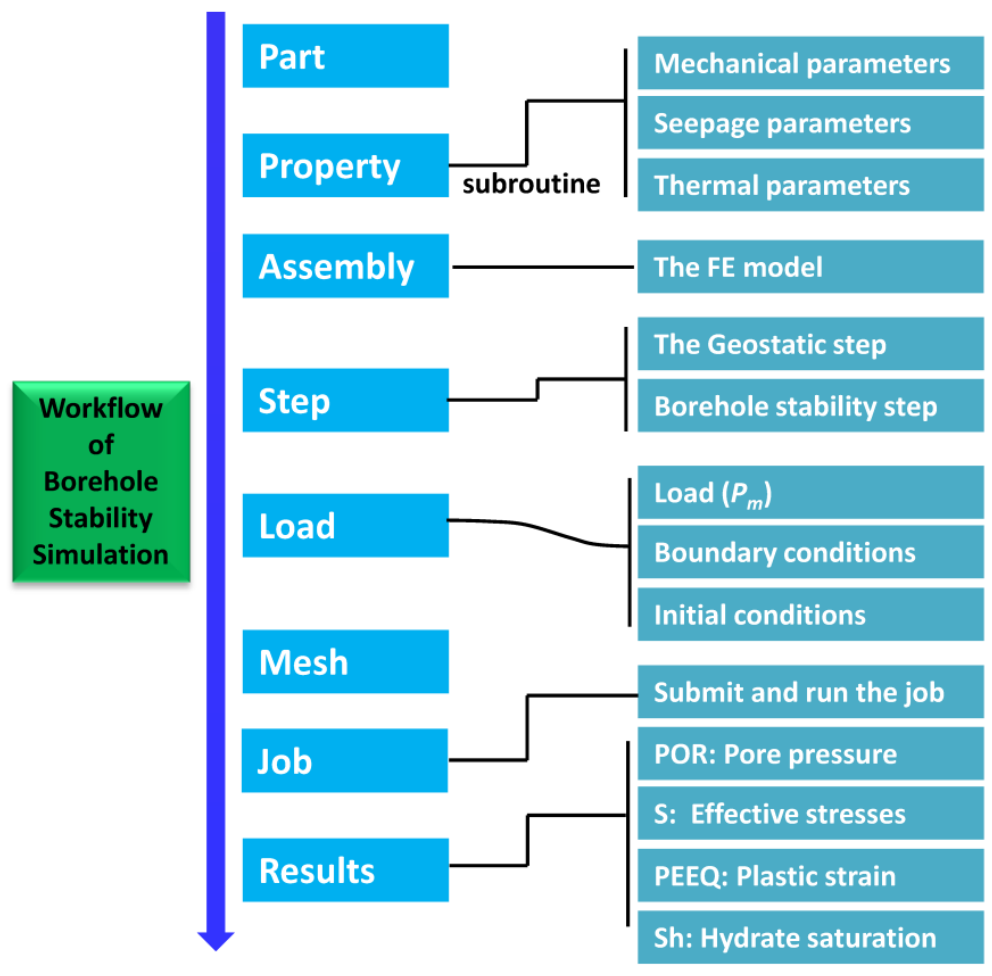

Figure 6: Workflow of borehole simulation in hydrate-bearing sediments.

\section{CASE STUDY}

\section{Basic input data for simulation}

7 he basic input data for investigation of borehole stability in the clayey silt hydrate-bearing sediments are listed in Tab. 2 and Tab. 3 [33]. However, the physical parameters of hydrate-bearing sediments are different from each other in different area all over the world for the difference in so many factors such as the lithology or hydrate saturation. Therefore, a series of empirical formulae describing the characteristics of hydrate reservoirs have been obtained from the research on artificial or natural hydrate samples.

\begin{tabular}{ccc|ccc}
\hline Parameter & Value & Unit & Parameter & Value & \\
Density, $\varrho$ & 2000 & $\mathrm{Kg} / \mathrm{m}^{3}$ & Thermal conductivity, $\lambda$ & 1.5 & $\mathrm{~W} /(\mathrm{m} \cdot \mathrm{K})$ \\
Initial Young's modulus, $E_{0}$ & 625 & $\mathrm{MPa}$ & Specific heat capacity, $C_{s b}$ & 1362 & $\mathrm{~J} /(\mathrm{Kg} \cdot \mathrm{K})$ \\
Initial dilation angle, $\psi$ & 17.46 & $\circ$ & Drilling mud pressure, $P_{m}$ & 15.5 & $\mathrm{MPa}$ \\
Poisson's ratio, $v$ & 0.35 & - & Drilling mud temperature, $T_{m}$ & 18.79 & ${ }^{\circ} \mathrm{C}$ \\
Friction angle, $\epsilon$ & 25 & $\circ$ & Drilling time, $t_{d}$ & 3 & $\mathrm{~h}$ \\
Initial cohesion, $C_{0}$ & 1.25 & $\mathrm{MPa}$ & Bias ratio & 5 & - \\
\hline
\end{tabular}

Table 2: Physical parameters of investigation model before hydrate dissociation and the drilling conditions. 
The relationship between Young's modulus of hydrate-bearing sediments $E$ and hydrate saturation $S_{b}$ can be expressed by Eqn. (8) [34].

$$
E=125+1000 \cdot S_{h}
$$

The cohesion $C$ also changes with hydrate saturation, and it can be expressed by the following equation

$$
C=2.5 \mathrm{MPa} \times S_{b}
$$

In addition, change of dilation angle caused by hydrate can be expressed by Eqn. (10).

$$
\sin \psi=0.05+0.5 \times S_{h}
$$

\begin{tabular}{ccc|ccc}
\hline Parameter & Value & Unit & Parameter & Value & Unit \\
Void ratio & 0.8512 & - & Initial hydrate saturation, $S_{b 0}$ & 47 & $\%$ \\
Initial pore pressure & 14.64 & $\mathrm{MPa}$ & Max. horizontal stress, $\sigma_{H},(\mathrm{Y})$ & 0.9 & $\mathrm{MPa}$ \\
Vertical effective stress, $\sigma_{V}$ & 1.1 & $\mathrm{MPa}$ & Min. horizontal stress, $\sigma h,(\mathrm{X})$ & 0.6 & $\mathrm{MPa}$ \\
Initial permeability, $k_{0}$ & $10^{-14}$ & $\mathrm{~m}^{2}$ & Initial temperature, $T$ & 14.79 & ${ }^{\circ} \mathrm{C}$ \\
Initial porosity, $\phi_{0}$ & 45.98 & $\%$ & & & \\
\hline
\end{tabular}

Table 3: Initial conditions of the FE model.

\section{Hydrate dissociation during the drilling operation}

In this case, the bottom-hole pressure $\left(P_{m}\right)$ is $15.5 \mathrm{MPa}$, which is larger than the initial pore pressure (14.64MPa). Therefore, the investigation case can be defined as the overbalanced drilling operation (ODB). The properties of hydrate-bearing sediments listed in Tab. 2 and Tab. 3 have been as close as possible to that of the hydrate reservoirs in the South China Sea. Although it is ODB case, the conditions of drilling mud pressure (i.e., $15.5 \mathrm{MPa})$ and its temperature $\left(17.79^{\circ} \mathrm{C}\right.$, which is higher than the phase equilibrium temperature calculated by drilling mud pressure) can result in the dissociation of seawater hydrates. Fig.7 shows the temperature distribution of at different drilling times along a path extending radially from the borehole.

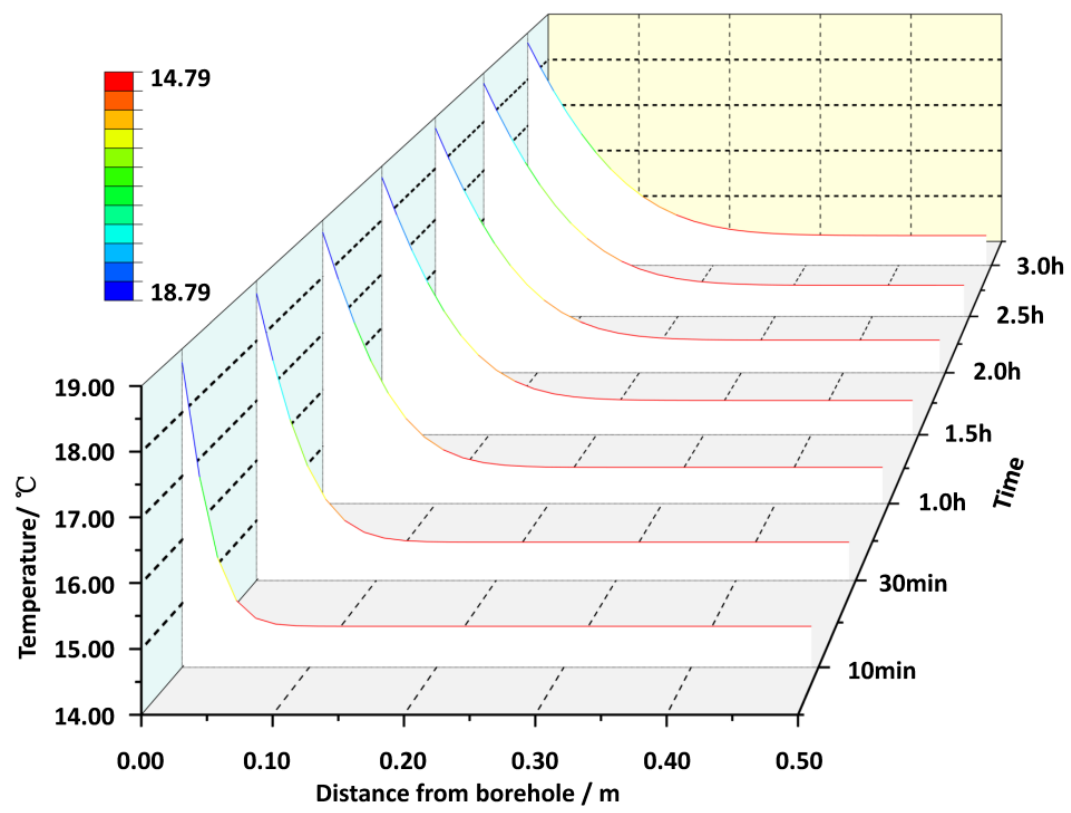

Figure 7: Temperature distribution of at different drilling times along a path extending radially from the borehole. 
From Fig.7, the temperature front gradually moves forward from the borehole, but its speed gradually slows down. When the formation is drilled for $10 \mathrm{~min}$, the temperature front reached a position of $4.30 \mathrm{~cm}$ from the borehole. However, the temperature front reaches the position of $35.72 \mathrm{~cm}$ when the hydrate-bearing sediment has been drilled for 3 hours. However, the temperature disturbance in the hydrate reservoir does not imply the hydrate dissociation. Fig. 8 shows the dissociation range of hydrate-bearing sediments within the near-wellbore area at different times. It can be seen from Fig. 8 that drilling operation only results in the hydrate dissociation within a range of $17.94 \mathrm{~cm}$ around the borehole in the nearwellbore area, which indicates the fact mentioned above that the temperature disturbance in the hydrate reservoir does not imply the hydrate dissociation. Therefore, only when both the pore pressure and temperature reach the dissociation condition of methane hydrates, hydrate dissociation can occur. By comparing the simulation results shown in Fig.7 and Fig.8, it can be seen that the dissociation speed of seawater hydrates in hydrate-bearing sediments during the drilling operation is similar to that of temperature front, and both speeds slow down as drilling operation continues.

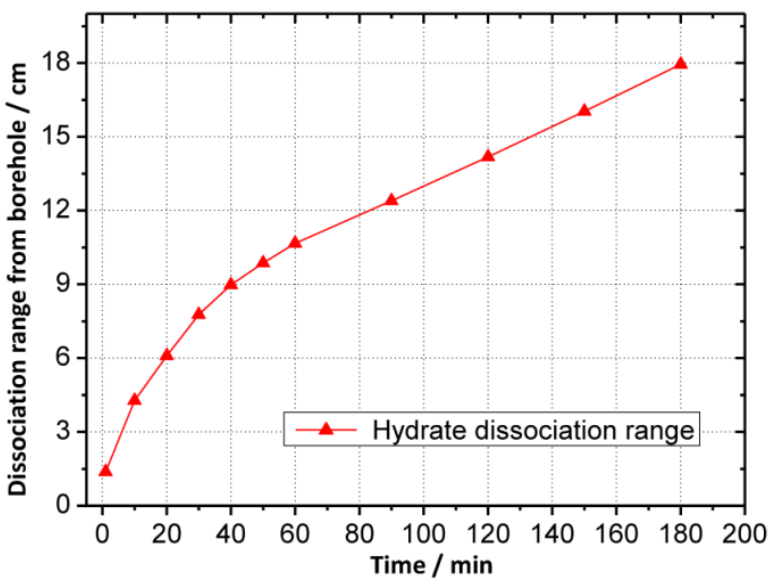

Figure 8: Dissociation range of hydrate-bearing sediments within the near-wellbore area.

\section{Yield area caused by bydrate dissociation}

The area where the equivalent plastic strain (PEEQ) generated is the area that borehole collapse may occur. Therefore, the equivalent plastic strain can be used as an important parameter to describe the borehole collapse/instability during a drilling operation in hydrate reservoirs. The evolution of yield range (where the PEEQ value is positive) within the nearwellbore area during the drilling operation in hydrate-bearing sediments of the South China Sea is demonstrated in Fig.9. As can be seen from Fig.9, within half an hour of the whole drilling operations, not only the yield range of the nearwellbore region, but also the maximum equivalent plastic strain continuously increase as drilling operation continues. However, although the yield range within the near-wellbore area changes little after half an hour of the drilling operation, the equivalent plastic strain (PEEQ) continues to increase rapidly. In spite of this, larger yield area where borehole collapse may occur can present with the increase of the dissociation area.

\section{Superiority and applicability of the coupled FE method}

In order to verify the superiority of the simulation method developed herein, results obtained from two different FE models are compared. Among them, a model is the finite element model proposed in this paper that couples seepage, deformation and heat transfer together (which is named as "Model 1"). The other is a simplified model that ignores seepage and heat transfer (which is defined as "Model 2"). Fig.10 shows the comparison results of equivalent plastic strain at last between these two different models described above. From Fig.1, the maximum collapse area should present at the direction of the minimum horizontal principal stress. However, as shown in Fig.10b, when the FE model neglects seepage and the heater transfer (Model 2), the yield area is evenly distributed along the borehole. Therefore, as can be seen from Fig.10, simulation of borehole collapse during the drilling operation in hydrate reservoirs is more realistic using the coupled FE model (Model 1) that integrates seepage, deformation and heat transfer. In addition, borehole collapse simulation with the FE model neglects seepage and the heater transfer (Model 2) overestimates the borehole collapse. Therefore, all these comparison results indicate the applicability of both the coupled FE method and the investigation method established herein. 

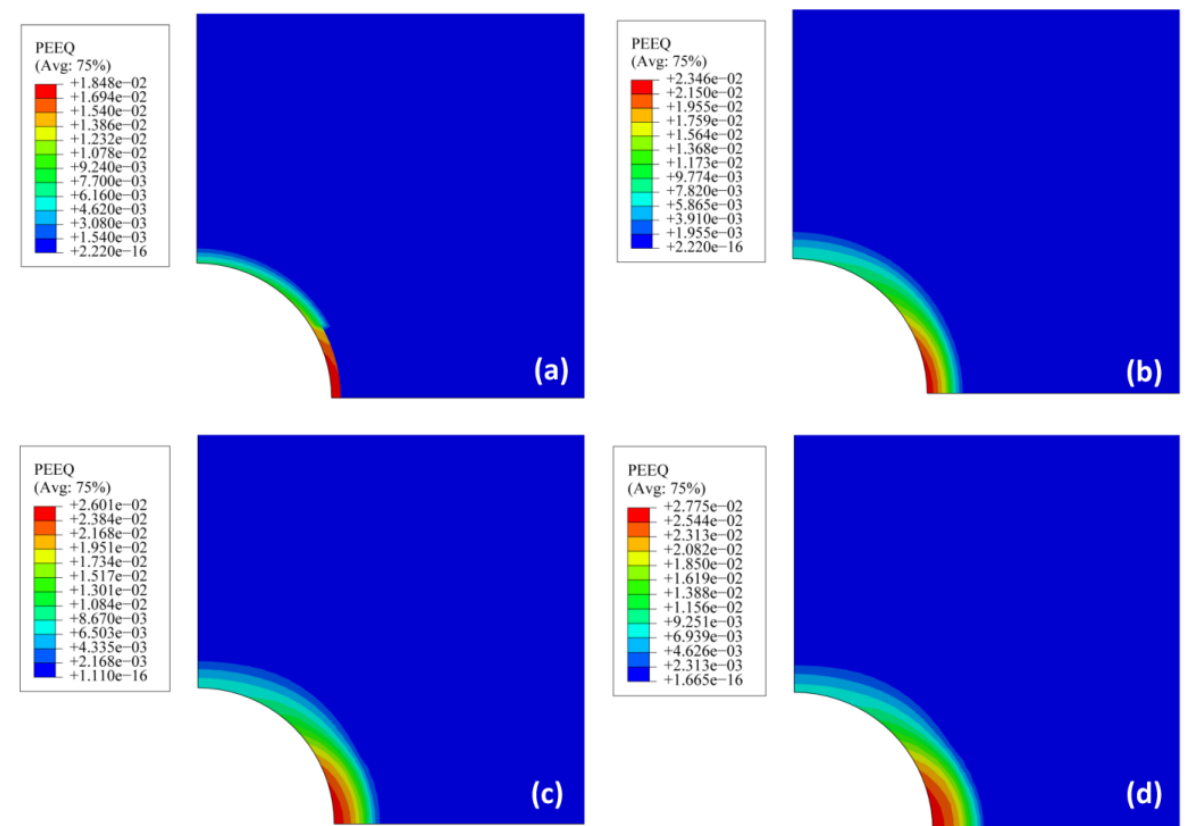

(c)
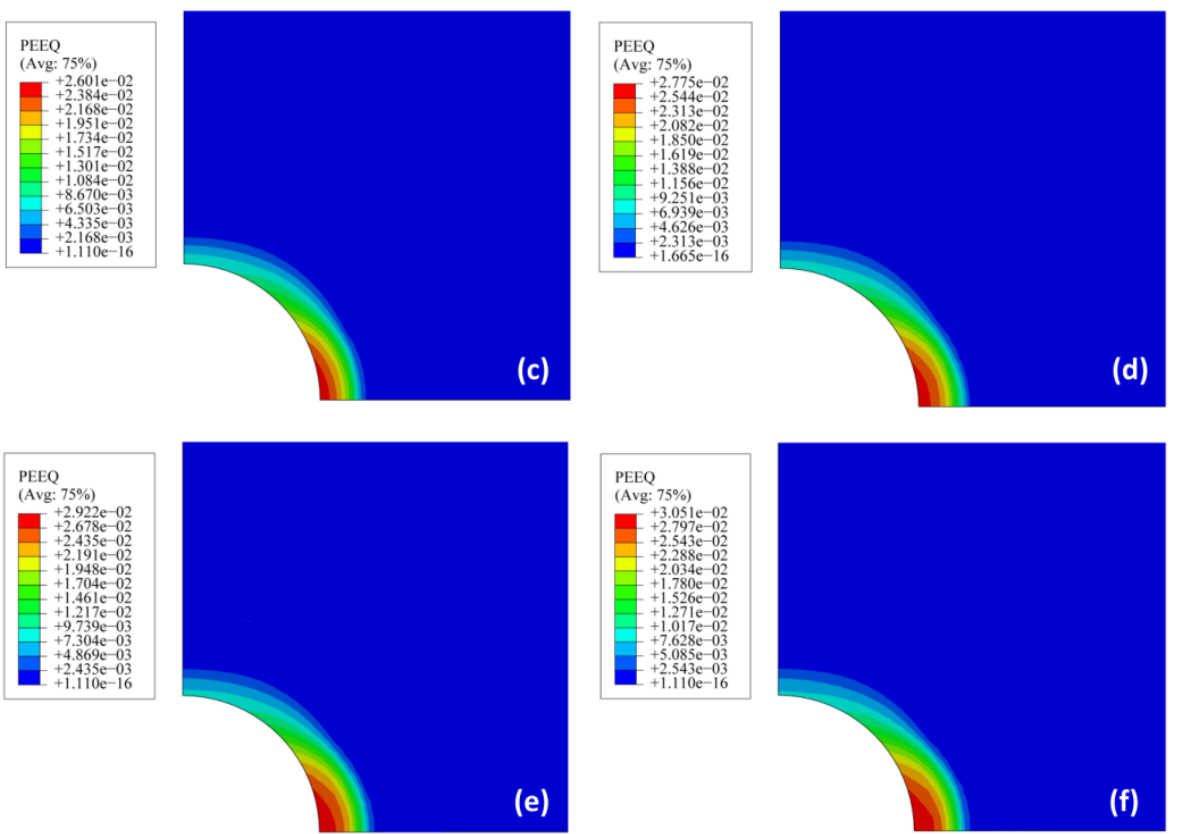

Figure 9: Equivalent plastic strain (PEEQ) within the near-wellbore area during drilling operation in hydrate-bearing sediments. (a): $1 \mathrm{~min},(\mathrm{~b}): 10 \mathrm{~min},(\mathrm{c}): 30 \mathrm{~min},(\mathrm{~d}): 1 \mathrm{~h},(\mathrm{e}): 2 \mathrm{~h},(\mathrm{f}): 3 \mathrm{~h}$
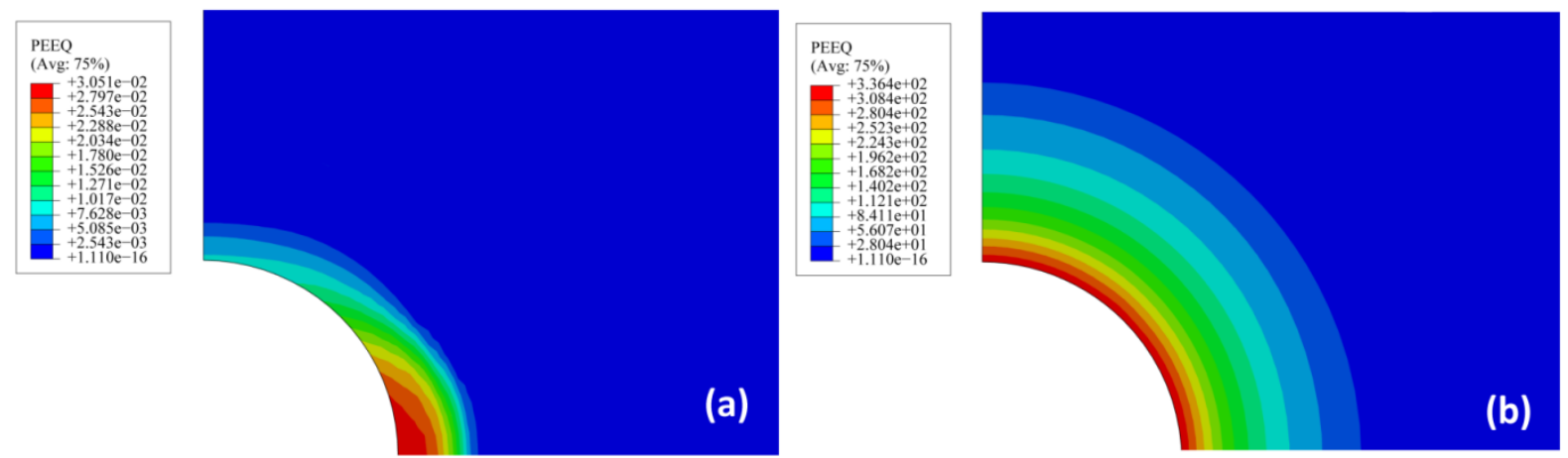

Figure 10: Comparison results of equivalent plastic strain at the last (drilling in hydrate formation for $3 \mathrm{~h}$ ) of the drilling operation between these two different models. (a): PEEQ of Model 1, (b): PEEQ of Model 2.

\section{Effect of mesh size on bydrate dissociation and borehole collapse}

Effect of mesh size on hydrate dissociation and borehole collapse are shown as Fig.11 and Fig.12 respectively. Herein, the Bias ratio (1 and 10 are investigated herein) has been defined a parameter to describe the size ratio between the maximum and the minimum elements within the near-wellbore region. It can be seen from Fig.11 that hydrates dissociate more when mesh quality of the FEM is not very good (Bias ratio is equal to 1). This is because hydrate dissociation within hydrate-bearing sediments during the analysis process is based on the temperature and pore pressure of each mesh element. The poor mesh quality makes the element interval within the near-wellbore area larger, resulting in faster hydrate 
dissociation. Conversely, the better mesh quality within the near-wellbore area means that the mesh size increases from the borehole radially outward, which makes the hydrate dissociation simulation closer to the actual situation.

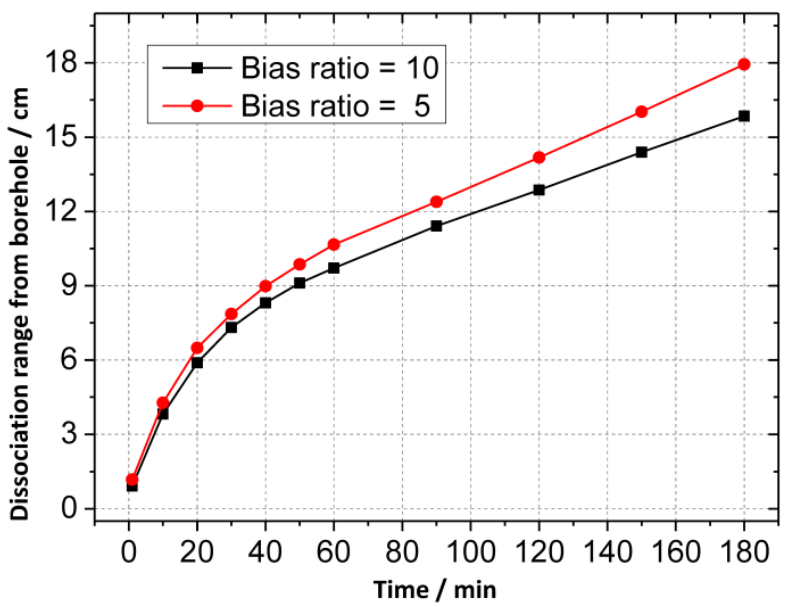

Figure 11: Dissociation range of hydrate-bearing sediments within the near-wellbore area when the Bisa ratio is different.

Fig.12 displays the equivalent plastic strain of the hydrate formation within the near-wellbore area at the last of the drilling operation when the mesh size is different. As can be seen from Fig.12, the equivalent plastic strain is larger when the mesh quality is good (when the Basi ratio is 5), this is related to the hydrate dissociation in Fig.11. When the mesh quality is poor, more hydrate dissociation leads to more severe wellbore collapse and instability. For example, when the Basi ratio is 10, the maximum equivalent plastic strain is $2.977 \times 10^{-2}$, but the maximum equivalent plastic strain increases to $3.051 \times 10^{-2}$ when the Basi ratio changes to 5 . In addition, the yield range caused by hydrate dissociation changes little for models with two different mesh sizes. All these results indicate that mesh size is an important factor when the FEM was used to investigate wellbore stability in hydrate-bearing sediments.
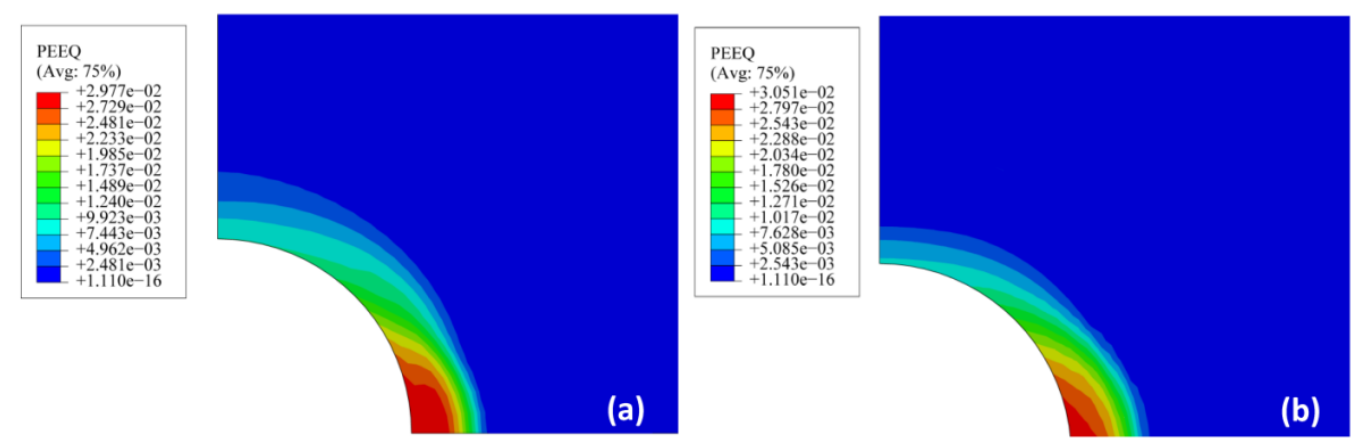

Figure 12: Comparison results of equivalent plastic strain at the last (drilling in hydrate formation for $3 \mathrm{~h}$ ) of the drilling operation between these two different mesh size within the near-wellbore area. (a): PEEQ when Basi ratio is 10, (b): PEEQ when Basi ratio is 5 .

\section{CONCLUSIONS AND SUGGESTIONS}

he major results are as follows:

(1) The investigation method of borehole collapse in hydrate-bearing sediments is developed, and a twodimensional seepage-deformation-heat transfer coupled finite element model is also established.

(2) Hydrate stability depends on so many factors, such as the temperature and the pore pressure. Only when both the pore pressure and temperature reach the dissociation condition of methane hydrate, hydrate dissociation can occur.

(3) Equivalent plastic strain caused by hydrate dissociation increases with the continuous drilling operation in hydratebearing sediments. And, borehole collapse first occurs at the intersection of the minimum horizontal principal stress direction with the borehole. 
(4) It is impractical to investigate borehole collapse using the simplified model that neglects both the seepage and the heat transfer (i.e., Model 2 in this paper). By comparison, the coupled finite element model and the investigation method established herein are feasible for simulating borehole instability during the drilling operation in hydrate-bearing sediments. (5) Poor mesh quality is not conducive to realistically simulating the hydrate dissociation during the drilling operation and the resulting wellbore collapse. Mesh size is also an important factor when the FEM was used to investigate wellbore stability in hydrate-bearing sediments.

Although the research method proposed in this paper has some advantages compared with previous studies, there are still many shortcomings and need further improvement:

(1) Effect of the anisotropy of reservoir properties on borehole collapse needs to be investigated.

(2) Effect of hydrate dissociation on temperature and pore pressure must be considered to realistically simulate the actual situation.

(3) A temperature change of drilling mud during mud circulation also a limitation requires to be considered.

\section{FUNDING}

7 his work is supported by Program for the Changiiang Scholars and Innovative Research Team in University (IRT_14R58), the National Natural Science Foundation Project of China (51704311), the Fundamental Research Funds for the Central Universities (Grant No. 16CX06033A), National Key Research and Development Program (Grant No. 2016YFC0304005), the National Basic Research Program of China (973 Program) (Grant No. 2015CB251201) and Qingdao Science and Technology Project (Grant No. 15-9-1-55-jch).

\section{ACKNOWLEDGEMENTS}

his work should be thankful for the help from Rock Mechanics Laboratory in China University of Petroleum (East China).

\section{REFERENCES}

[1] Gai, X. and Sánchez, M. (2017). A geomechanical model for gas hydrate-bearing sediments, Journal of Environmental Geotechnics, 4(2), pp.143-156. DOI: 10.1680/jenge.15.00050.

[2] Klar, A., Soga, K. and Ng, MYA. (2017). Coupled deformation-flow analysis for methane hydrate extraction, Géotechnique, 60(10), pp.765-776. DOI: 10.1680/geot.9.P.079-3799.

[3] Lu, S. (2015). RETRACTED: A global survey of gas hydrate development and reserves: Specifically in the marine field, Renewable \& Sustainable Energy Reviews, 41, pp.884-900. DOI: 10.1016/j.rser.2014.08.063.

[4] Li, G., Li, X. Zhang, K. Li, B. and Zhang, Y. (2013). Effects of Impermeable Boundaries on Gas Production from Hy drate Accumulations in the Shenhu Area of the South China Sea, Energies, 6, pp. 4078-4096.

DOI: $10.3390 /$ en6084078.

[5] Merey, S. (2016). Drilling of gas hydrate reservoirs, Journal of Natural Gas Sciences \& engineering, 35, pp.1167-1179. DOI: 10.1016/j.jngse.2016.09.058.

[6] Milkov, AV. (2004). Global estimates of hydrate-bound gas in marine sediments: how much is really out there, Earth Science Reviews, 66(3), pp.183-197. DOI: 10.1016/j.earscirev.2003.11.002.

[7] Zhang, W., Bai, F. Shao, M. and Tian, Q. (2017). Progress of offshore natural gas hydrate production tests in Japan and implication, Marine and Geology Quaternary Geology, 37(5), pp.27-33. (In Chinese)

[8] Li, G., Moridis, GJ. Zhang, K. and Li, XS. (2011). The use of huff and puff method in a single horizontal well in gas production from marine gas hydrate deposits in the Shenhu Area of South China Sea, Journal of Petroleum Science \& Engineering, 77(1), pp.49-68. DOI: 10.1016/j.petrol.2011.02.009.

[9] Cha, Y., Yun, TS. Kim, YJ. Lee, JY. and Kwon, T. (2016). Geomechanical, Hydraulic and Thermal Characteristics of Deep Oceanic Sandy Sediments Recovered during the Second Ulleung Basin Gas Hydrate Expedition, Energies, 9(10), pp. 775. DOI: 10.3390/en9100775. 
[10] Rutqvist, J. and Moridis, GJ. (2007). Numerical Studies on the Geomechanical Stability of Hydrate-Bearing Sediments. SPE Journal, 14(2), pp.267-282. DOI: 10.2118/126129-PA.

[11] Klar, A., Uchida, S. Soga, K. and Yamamoto, K. (2013). Explicitly Coupled Thermal Flow Mechanical Formulation for Gas-Hydrate Sediments, SPE Journal, 18(2), pp.196-206. DOI: 10.2118/162859-PA.

[12] Pook, Les. (2015). Crack paths and the linear elastic analysis of cracked bodies, Frattura ed Integrità Strutturale, 9, pp.150-159. DOI: 10.3221/IGF-ESIS.34.16.

[13] Berto, F., Campagnolo, A. and Pook, L. (2015). Three-dimensional effects on cracked components under anti-plane loading, Frattura ed Integrità Strutturale, 33, pp.17-24. DOI: 10.3221/IGF-ESIS.33.03.

[14] Qiu, K. B., Yamamoto, K. Birchwood, R. A. and Chen, Y. R. (2015). Well Integrity Evaluation for Methane Hydrate Production in the Deepwater Nankai Trough, SPE Drilling \& Completion, 30(1), SPE-174081-PA.

DOI: $10.2118 / 174081-\mathrm{PA}$

[15] Ning, F.L., Zhang, K.N. Wu, N.Y. Zhang, L. Li, G. Jiang, G. S. Yu, Y.B. Liu, L. and Qin, Y.H. (2013). Invasion of drilling mud into gas-hydrate-bearing sediments. Part I: effect of drilling mud properties, Geophysical Journal International, 193(3), pp.1370-1384. DOI: 10.1093/gii/ggt015.

[16] Ning, F.L, Wu, N.Y. Yu, Y.B. Zhang, K.N. Jiang, G.S. Zhang, L. Sun, J.X. and Zheng, M.M. (2013). Invasion of drilling mud into gas-hydrate-bearing sediments. Part II: Effects of geophysical properties of sediments, Geophysical Journal International, 193(3), pp.1385-1398. DOI: 10.1093/gji/ggt016.

[17] Fereidounpour, A., and Vatani, A. (2015). Designing a Polyacrylate drilling fluid system to improve wellbore stability i $\mathrm{n}$ hydrate bearing sediments, Journal of Natural Gas Science and Engineering, 26, pp. 921-926.

DOI: 10.1016/j.jngse.2015.06.038.

[18] Matsuda, H., Yamakawa, T. Sugai, Y.C. and Sasaki, K. (2016). Gas Production from Offshore Methane Hydrate Layer and Seabed Subsidence by Depressurization Method, Engineering, 8, pp.353-364. DOI: 10.4236/eng.2016.86033.

[19] McConnell, D.R., Zhang, Z.J. and Boswell, R. (2012). Review of progress in evaluating gas hydrate drilling hazards, Marine \& Petroleum Geology, 34, pp.209-223. DOI: 10.1016/j.marpetgeo.2012.02.010.

[20] Wang, X.J., Lee, M. Collett, T. Yang, S.X. Guo, Y.Q. and Wu, S.G. (2014). Gas hydrate identified in sand-rich inferred sedimentary section using downhole logging and seismic data in Shenhu area, South China Sea, Marine and Petroleum Geology, 51, pp.298-306. DOI: 10.1016/j.marpetgeo.2014.01.002.

[21] Su, Z., Moridis, G.J. Zhang, K.N. Yang, R. and Wu, N.Y. (2010). SS-Gas Hydrate: Numerical Investigation of Gas Production Strategy for the Hydrate Deposits in the Shenhu Area, In: Proceding of Offshore Technology Conference, Houston, USA, OTC-20551-MS. DOI: 10.4043/20551-MS.

[22] Su, Z., Huang, L. Wu, N.Y. and Yang, S.X. (2013). Effect of thermal stimulation on gas production from hydrate dep osits in Shenhu area of the South China Sea, Science China Earth Sciences, 56(4), pp.601-610.

DOI: $10.1007 /$ s11430-013-4587-4.

[23] Moridis, G.J. and Reagan, M.T. (2007). Strategies for Gas Production From Oceanic Class 3 Hydrate Accumulations, In: Proceding of Offshore Technology Conference, Houston, USA, OTC-18865-MS. DOI: 10.4043/18865-MS.

[24] Khanna, A., Luong, H. Kotousov, A. Nguyen, G. and Rose, L. (2017). Residual opening of hydraulic fractures created using the channel fracturing technique, International Journal of Rock Mechanics and Mining Sciences, 100, pp.124137. DOI: $10.1016 /$ j.ijrmms.2017.10.023.

[25] Bortolan Neto, L. and Kotooussov, A. (2012). Residual opening of hydraulically stimulated fractures filled with granular particles, Journal of Petroleum Science and Engineering, 100, pp.24-29.

[26] Freij-Ayoub, R., Tan, C. Clennell, B. Tohidi, B. and Yang, J.H. (2007). A wellbore stability model for hydrate bearing sediments, Journal of Petroleum Science and Engineering, 57, pp.209-220. DOI: 10.1016/j.petrol.2005.10.011.

[27] Meneghetti, G., Campagnolo, A., Berto, F. and Tanaka, K. (2017). Crack initiation life in notched Ti-6Al-4V titanium bars under uniaxial and multiaxial fatigue: Synthesis based on the averaged strain energy density approach, Frattura ed Integrita Strutturale, 11, pp.8-15. DOI: 10.3221/IGF-ESIS.41.02.

[28] Bradley, W. (1979). Failure of Inclined Boreholes, Journal of Energy Resources Technology, 101(4), pp.232-239. DOI: 10.1115/1.3446925.

[29] Liu, X., Zeng, W. Liang, L. and Lei, M. (2016). Wellbore stability analysis for horizontal wells in shale formations, Journal of Natural Gas Science \& Engineering, 31, pp.1-8. DOI: 10.1016/j.jngse.2016.02.061.

[30] Liu, M., Yan, J. Lu, Y. Chen, M. Hou, B. Chen, W. Wen, X. and Yu, X. (2016). A Wellbore Stability Model for a Deviated Well in a Transversely Isotropic Formation Considering Poroelastic Effects, Rock Mechanics and Rock Engineering, 49(9), pp.3671-3686. DOI: 10.1007/s00603-016-1019-8.

[31] Aadnoy, B.S., and Chenevert, M.E. (1987). Stability of highly inclined boreholes, SPE Drilling Engineering, 2, pp.364374. DOI: $10.2118 / 16052-P A$. 
[32] Loh, M., Falser, S. Babu, P. Linga, P. Palmer, A. and Tan, T. S. (2012). Dissociation of Fresh- And Seawater Hydrates along the Phase Boundaries between 2.3 and $17 \mathrm{MPa}$, Energy \& Fuels, 26(10), pp.6240-6246.

DOI: $10.1021 /$ ef3008954.

[33] Li, Q., Cheng, Y. Li, Q. Zhang, C. Ansari, U. and Song, B. (2018). Establishment and evaluation of strength criterion for clayey silt hydrate bearing sediment, Energy Sources, Part A: Recovery, Utilization, and Environmental Effects, 40(6), pp.742-750. DOI: 10.1080/15567036.2018.1457742.

[34] Ng, M.Y.A., Klar, A. and Soga, K. (2008). Coupled soil deformation-flow-thermal analysis of methane production in layered methane hydrate soils, In Proceedings of the Offshore Technology Conference, Houston, TX, USA, 5-8.

\section{NOMENCLATURE}

\begin{tabular}{cl|cl}
\hline Symbol & \multicolumn{1}{c|}{ Interpretation } & Symbol & \multicolumn{1}{c}{ Interpretation } \\
$\sigma_{t o t}$ & The total stress, $\mathrm{MPa}$ & $A z$ and Inc & The azimuth and the inclination, \\
$\sigma_{e f f}$ & The effective stress, $\mathrm{MPa}$ & $P_{m}$ & Drilling mud pressure, $\mathrm{MPa}$ \\
$P_{p}$ & The pore pressure, $\mathrm{MPa}$ & $v$ & The Poisson's ratio \\
$\sigma_{P}$ & The in-situ stress tenser, $\mathrm{MPa}$ & $\theta$ & $\begin{array}{l}\text { The polar angle in borehole cylindrical } \\
\text { coordinate system }\end{array}$ \\
$\mathrm{R}_{S}$ and $\mathrm{R}_{B}$ & The transformation matrices & $T_{e q}$ & Equilibrium temperature of methane hydrate \\
$\alpha, \beta$ and $\gamma$ & Three rotation angles, ${ }^{\circ}$ & $P_{e q}$ & Equilibrium pressure of methane hydrate \\
\hline
\end{tabular}

